\title{
Assessment practice of geomechanical risks for slopes and retaining walls
}

\author{
Boris Polovov, Niyaz V aliev, Maksim Volkov, and Maksim Lebzin \\ U ral State M ining University, 620144, Ekaterinburg, Russia
}

\begin{abstract}
The methods of geomechanical analysis are considered, which together allow to correct and propose new proactive approaches to ensure the geomechanical safety of slopes and retaining walls of mining structures. A very promising solution to this problem is the addition of a traditional deterministic measure for assessing the condition of slopes and retaining walls, i.e. safety margin factors, with simulation quantitative assessments of risk levels that objectively reflect the instability of the environment. In such a complex, the deterministic block performs insurance functions and determines that the results of the analysis do not contradict the requirements of regulatory documents; simulation (according to the M onte Carlo method) provides an unambiguous solution on the factors of economic and social security, eliminates or significantly reduces the likelihood of making unnecessary costs.
\end{abstract}

\section{Introduction}

The geomechanical analysis of slopes and retaining walls is based on a vast practical experience, a large amount of experimental materials, analytical and numerical studies of reputable scientists and scientific organizations. Currently, the methods of geomechanical analysis in the context of ensuring geomechanical safety are regulated in all-Russian and industry regulatory documents. Despite the long-term practice of implementing and $\neg$ improving the existing regulatory documents, including $\neg$ a system of insuring factors for stability, safety, overload, working conditions, $\neg$ significance of the facility, etc., injuries, accidents and catastrophes of a geomechanical nature are not excluded and, by no means, $\neg$ have not stopped. The main reason for this situation is the random nature of the initial information about the enclosing rocks masses. In this regard, it is necessary to develop new methods of geomechanical analysis, which together allow us to correct and propose new productive approaches to ensure geomechanical safety. A very promising solution to this problem is the addition of a traditional deterministic measure for assessing the condition of slopes and retaining walls, i.e. safety margin factors, with simulation quantitative assessments of risk levels that objectively reflect the instability of the environment. In such a complex, the deterministic block performs insurance functions and determines that the results of the analysis do not contradict the requirements of regulatory documents; simulation (according to the Monte Carlo method) provides an unambiguous solution on the factors of economic and social security, eliminates or significantly reduces the likelihood of making unnecessary costs. High adequacy of simulation modeling of 
geomechanical risks is achieved $[1 \div 6]$ as a result of applying tested models, input information about the enclosing masses and indicators of physical and technical properties of rocks processed by non-parametric statistics, restoration and replication of statistical samples obtained during exploration and field experiments, by the formation of simulation models based on a modified simulation designer [7], stopping the shortcomings and errors of the Monte Carlo method.

The purpose of this paper is to show, with concrete examples, the feasibility and advantages of an integrated deterministic-probabilistic approach, the high quality of the simulation component of the complex, the availability of developed computer technologies to a wide range of potential users, and the speed of their implementation on ordinary computer equipment.

\section{Methods of geomechanical risks analysis}

Due to limitations of the volume of the materials presented, eight adapted models of typical geomechanical situations are considered in the article. Digital arrays that generate dozens and hundreds of input and final random numbers in professional models are replaced with small digital fragments, tabular material and drawings that perform demonstration functions. The distribution of random numbers in demo models is postulated by the normal Gauss law. Meanwhile: "Classical statistical methods usually assume a normality of distribution, which, strictly speaking, is never satisfied, so that any application of these methods leaves a sense of danger of error" [8, p. 124].

\section{Slopes of mining facilities}

Vertical bank slope work in the ultimate contour of open-cuts. The height of the stable vertical bank $H_{90}$ and the levels of geomechanical risks are established on the basis of the formula:

$$
H_{90}=2 C \operatorname{ctg}\left(45^{\circ}-\rho / 2\right) \gamma^{-1} \eta^{-1}
$$
factor.

where $C$ - adhesion; $\rho$ - internal friction angle; $\gamma$ - rock gravity: $\eta$ - general partial

The conditions for the effective application of formula (1) are the following: reliability of determination and physicomechanical characteristics $C, \rho, \gamma ;$ checking random information for random sampling, rejecting coarse outbreaks, evaluating sample distributions, determining the homogeneity of a geomechanical object along the strike of banks. The deterministic and simulation models in accordance with formula (1) have the programmatic form:

$$
\begin{gathered}
\mathrm{H} 90=2 * \mathrm{M}(4) /(\mathrm{M}(1) * \mathrm{M}(2) * \mathrm{TAN}(\mathrm{PI} / 4-\mathrm{M}(3) / 2)) \\
\mathrm{YA}(\mathrm{I})=2 * \mathrm{~B} 1(4, \mathrm{I}) /(\mathrm{B} 1(1, \mathrm{I}) * \mathrm{~B} 1(2, \mathrm{I}) * \mathrm{TAN}(\mathrm{PI} / 4-\mathrm{B} 1(3, \mathrm{I}) / 2)),
\end{gathered}
$$

where $\mathrm{H} 90$ - the result of a deterministic calculation; $\mathrm{M}(1) \div \mathrm{M}(4)$ - average sampling random parameters $\eta, \gamma, \rho, C$; YA(I) - final array of $i$-th generated random values of the slope: $\mathrm{B} 1(1, \mathrm{I}) \div \mathrm{B} 1(4, \mathrm{I})$ - four $i$-th generated arrays of input random numbers.

Example. Source data: generation number of random numbers 135; random number distributions $\gamma, \rho, C$ - normal, $\eta$ - one-sided normal; sample means $\mathrm{M}(1)==1,1 ; \mathrm{M}(2)=$ $2,7 \mathrm{kN} / \mathrm{m}^{3} ; \mathrm{M}(3)=35^{\circ} ; \mathrm{M}(4)=200 \mathrm{kPa}$; standards (in accordance with clause 5.5 of the 
updated version of GOST 20522-2012) $\mathrm{S}(2)=\mathrm{M}(2) * 0,15 ; \mathrm{S}(3)=\mathrm{M}(3) * 0,3 ; \mathrm{S}(4)==$ $\mathrm{M}(4) * 0,3$; standard $\mathrm{S}(1)=(1,1-1,0) / 3$.

$\begin{array}{clllllllllll} & 1.003 & 1.054 & 1.044 & 1.008 & 1.052 & 1.038 & 1.054 & 1.040 & 1.059 & \\ \eta & 1.012 & 1.086 & 1.022 & 1.023 & 1.111 & 1.019 & 1.014 & 1.053 & 1.025 \ldots & \ldots \\ \gamma, & 20.327 & 28.547 & 24.161 & 23.279 & 32.285 & 33.403 & 31.022 & 25.117 & 25.173 & \\ \mathrm{kN} / \mathrm{m}^{3} & 23.601 & 17.768 & 27.961 & 26.264 & 23.380 & 25.848 & 21.621 & 34.484 & 24.575 & \ldots \\ \rho, & 0.410 & 0.545 & 0.325 & 0.457 & 0.666 & 0.699 & 0.397 & 0.698 & 0.598 & \\ \text { degree } & 0.717 & 0.990 & 0.756 & 0.845 & 0.734 & 0.821 & 0.308 & 0.579 & 0.518 \ldots & \\ \mathrm{C}, \mathrm{kPa} & 168.860 & 106.473 & 293.513 & 139.457 & 117.144 & 229.018 & 213.386 & 290.662 & 229.621 \\ & 153.648 & 206.984 & 220.983 & 100.356 & 149.425 & 258.370 & 109.482 & 163.410 & 125.412 \ldots\end{array}$

Final random slope height values after software rejection and sorting:

$\begin{array}{cccccccccc}\mathbf{8 . 1 9 1} & \mathbf{9 . 2 7 5} & \mathbf{9 . 5 1 8} & \mathbf{9 . 7 2 2} & \mathbf{1 0 . 0 1 5} & \mathbf{1 2 . 5 5 5} & \mathbf{1 3 . 0 0 6} & \mathbf{1 3 . 6 5 8} & \mathbf{1 4 . 1 1 6} \\ 14.196 & 14.346 & 14.419 & 14.509 & 15.524 & 15.653 & 15.950 & 16.026 & 16.109 \\ 16.644 & 16.753 & 17.062 & 17.146 & 17.992 & 18.336 & 18.871 & 18.872 & 18.873 \\ 19.079 & 19.165 & 19.580 & 19.611 & 19.670 & 19.683 & 20.141 & 20.484 & 20.803 \\ 20.837 & 20.845 & 20.921 & 20.965 & 21.081 & 21.112 & 21.221 & 21.317 & 21.321 \\ 21.342 & 21.820 & 22.285 & 22.497 & 22.907 & 22.910 & 22.937 & 23.832 & 24.658 \\ 24.813 & 24.855 & 24.955 & 25.159 & 25.270 & 25.857 & 25.883 & 25.909 & 26.139 \\ 26.326 & 26.403 & 26.459 & 26.551 & 26.753 & 26.890 & 27.011 & 27.327 & 27.353 \\ 27.408 & 27.517 & 27.542 & 27.654 & 28.277 & 28.285 & 28.335 & 28.577 & 29.192 \\ 29.245 & 29.422 & 29.449 & 29.567 & 29.963 & 30.920 & 31.211 & 31.374 & 31.377 \\ 31.733 & 31.958 & 32.085 & 32.391 & 32.469 & 32.604 & 32.962 & 33.512 & 33.555 \\ 34.184 & 34.403 & 34.583 & 35.545 & 35.843 & 35.982 & 36.680 & 36.892 & 36.917 \\ 37.274 & 37.641 & 37.822 & 37.880 & 37.937 & 38.643 & 40.289 & 40.355 & 40.977 \\ 42.804 & 43.645 & 43.907 & 44.456 & 45.031 & 45.186 & 47.714 & 47.854 & 48.840 \\ & 49.825 & 50.093 & 50.721 & 53.912 & 53.976 & 61.965 & 71.846 & \end{array}$

Assessment of the geomechanical risk $R_{H}$ for a given height of the bank $H$ is performed by the ratio:

$$
R_{H}=N / V \text {, }
$$

where $N$ - the number of random numbers YA (I) $<H$ in the resulting random array; $V-$ the volume of the resulting array after the rejection of errors.

For $H=10 \mathrm{~m}, N=4$ (in bold) and $V=133$ the risk is $R_{H}=4 / 133=0,03$. Thus, for a bank length of $1000 \mathrm{~m}$, the size of the deformable section will be $3 \mathrm{~m}$. Similarly, for given heights of $15,20,25 \mathrm{~m}$, the risks, respectively, will be: $0.0977,0.248,0.4386$.

Sustainability assessment of the open pit side. The deterministic assessment is performed according to the formulas defining a family of sliding surfaces from two conjugate arcs of "biarcs" (Fig. 1) with the calculation of the safety factors for each surface with subsequent selection of the surface with a minimum margin value:

$$
\begin{aligned}
& R_{1}=\frac{\left(x_{\mathrm{B}}-x_{A}\right) \sin \left(\frac{\varphi_{0}+\varphi_{2}}{2}\right)-\left(y_{B}-y_{A}\right) \cos \left(\frac{\varphi_{0}+\varphi_{2}}{2}\right)}{2 \sin \left(\frac{\varphi_{1}-\varphi_{0}}{2}\right) \sin \left(\frac{\varphi_{1}-\varphi_{2}}{2}\right)} ; \\
& R_{2}=\frac{\left(x_{\ddot{A}}-x_{B}\right) \sin \left(\frac{\varphi_{0}+\varphi_{1}}{2}\right)-\left(y_{\ddot{A}}-y_{B}\right) \cos \left(\frac{\varphi_{0}+\varphi_{1}}{2}\right)}{2 \sin \left(\frac{\varphi_{2}-\varphi_{0}}{2}\right) \sin \left(\frac{\varphi_{1}-\varphi_{2}}{2}\right)} ;
\end{aligned}
$$




$$
\left.\begin{array}{c}
x_{0_{1}}=x_{A}-R_{1} \sin \varphi_{1} \\
y_{0_{1}}=y_{A}+R_{1} \cos \varphi_{1} \\
x_{0_{2}}=x_{D}-R_{2} \sin \varphi_{2} \\
y_{0_{2}}=y_{D}+R_{2} \cos \varphi_{2} \\
x_{S}=R_{1} \sin \varphi_{0}+x_{0_{1}} \\
y_{S}=y_{0_{1}}-R_{1} \cos \varphi_{0}
\end{array}\right\},
$$

where $R_{1}$ and $R_{2}$ are the radii of the conjugate arcs; $R_{1}$ and $R_{2}, x_{O 1}, y_{O 1}, x_{O 2}, y_{O 2}$ coordinates of the rotation centers; $x_{S}, y_{S}-$ coordinates of the conjugation point $B$ of two arcs with radii $R_{1}$ и $R_{2}$ (Fig. 4); $\varphi_{1}=\alpha-45^{\circ}+\rho / 2 ; \varphi_{2}=45^{\circ}+\rho / 2$ or $\varphi_{2}=\delta-\theta ; \varphi_{0}=\left(\varphi_{2}-\varphi_{1}\right) n^{-1} ; x_{A}, y_{A}, x_{D}, y_{D}$ coordinates of the start and end points of the curved section of the sliding surface; $\alpha$ - bank slope angle; $\rho$-angle of internal friction; $\delta$ - angle of incidence of the weakening surface; $\theta-$ the angle of the "meeting" of the curved portion of the sliding surface with the weakening surface; $n_{3}-$ safety factor; $N_{i}$ - integral of the normal component of the load over the sliding surface; $c_{j}$ - conjunction; $L_{j}$ - integral of the length of the sliding surface; $T_{i}$ - integral of the tangent component of the load over the sliding surface; $m_{1}, m_{2}$ - values characterizing the features of the location of the sliding surfaces and the mode of occurrence of rocks.

Sliding surfaces are defined by two cycles $Y$ (the number of "beams" of biarcs) and $J$ (the number of biarcs in the beam). For each sliding surface, the safety factor is calculated and the calculated surface with the minimum safety factor is found, Fig. 1.

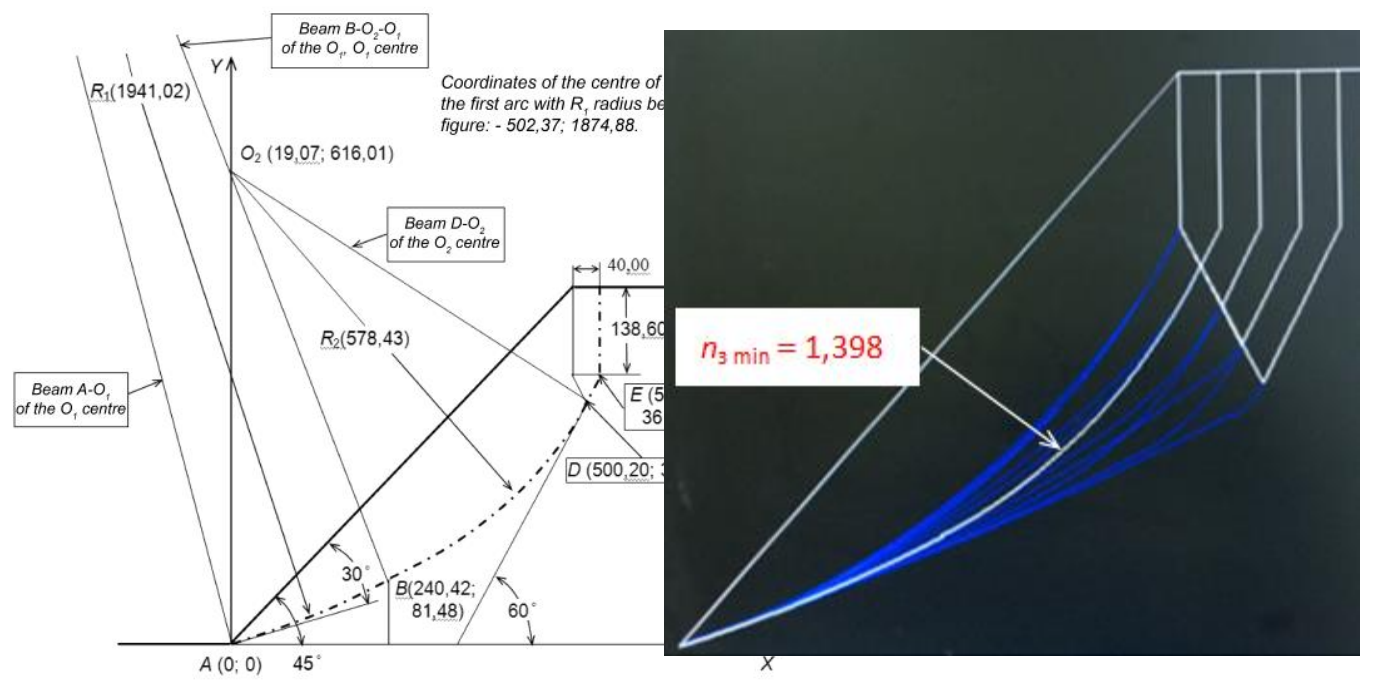

Fig. 1. Scheme of constructing sliding surfaces and surface search with a minimum safety factor.

Example. Source data: $\gamma=25 \mathrm{kN} / \mathrm{m}^{3} ; \rho=30^{\circ} ; \mathrm{C}=1000 \mathrm{kN} / \mathrm{m}^{2}$; side height $500 \mathrm{~m}$; overall band liquidation angle $45^{\circ}$ : statistics of random parameters $\gamma, \rho, \mathrm{C}$ are determined by the normal distribution. Fig. 1 and tab. 1 show the results of deterministic calculations of the safety factors $n_{3}$, surface with a minimum margin is highlighted in red. 
Table 1. Band safety margin factors.

\begin{tabular}{|c|c|c|c|c|c|c|c|c|c|c|c|}
\hline \begin{tabular}{|l} 
Cycle \\
$Y$
\end{tabular} & $\begin{array}{c}\text { Cycle } \\
J\end{array}$ & $n_{3}$ & $\begin{array}{c}\text { Cycle } \\
Y\end{array}$ & $\begin{array}{c}\text { Cycle } \\
J\end{array}$ & $n_{3}$ & $\begin{array}{c}\text { Cycle } \\
Y\end{array}$ & $\begin{array}{c}\text { Cycle } \\
J\end{array}$ & $n_{3}$ & $\begin{array}{c}\text { Cycle } \\
Y\end{array}$ & $\begin{array}{c}\text { Cycle } \\
J\end{array}$ & $n_{3}$ \\
\hline \multirow{4}{*}{1} & 1 & 1.423 & \multirow{4}{*}{2} & 1 & 1.398 & \multirow{4}{*}{3} & 1 & 1.445 & \multirow{4}{*}{4} & 1 & 1.547 \\
\hline & 2 & 1.428 & & 2 & 1.407 & & 2 & 1.445 & & 2 & 1.549 \\
\hline & 3 & 1.433 & & 3 & 1.413 & & 3 & 1.457 & & - & - \\
\hline & 4 & 1.436 & & 4 & 1.416 & & - & - & & - & - \\
\hline
\end{tabular}

For a selected surface with a minimum margin of stability by the Monte Carlo method, an array of random ones is formed, the risk of stability loss is set, which is 0.119 , and the reliability $1-0,119=0,881$ of the objects. The result of deterministic calculation: $n_{3}=1,398$ exceeds the standard safety factor $n_{3}$ normal equal to 1.3 , the reliability of 0.881 is greater than the confidence coefficient of 0.85 for the second group of limit states, so the pit board has acceptable stability.

Slope stability assessment at the design stage. In the deterministic block, the initial value of the slope angle is set according to $\alpha$ - formulas $(5) \div(8)$, modified in accordance with Fig. 2 . The sliding surface with is found a minimum safety factor $n_{3} \min$. If the found value differs from the standard margin, the correction value $\alpha \pm \Delta \alpha$ of the sliding surface search procedure with $n_{3} \min$ is uploaded into the program and the slope angle corrections are repeated until the condition $n_{3 \min }>\approx n_{3 \text { normal }}$ is fulfilled.

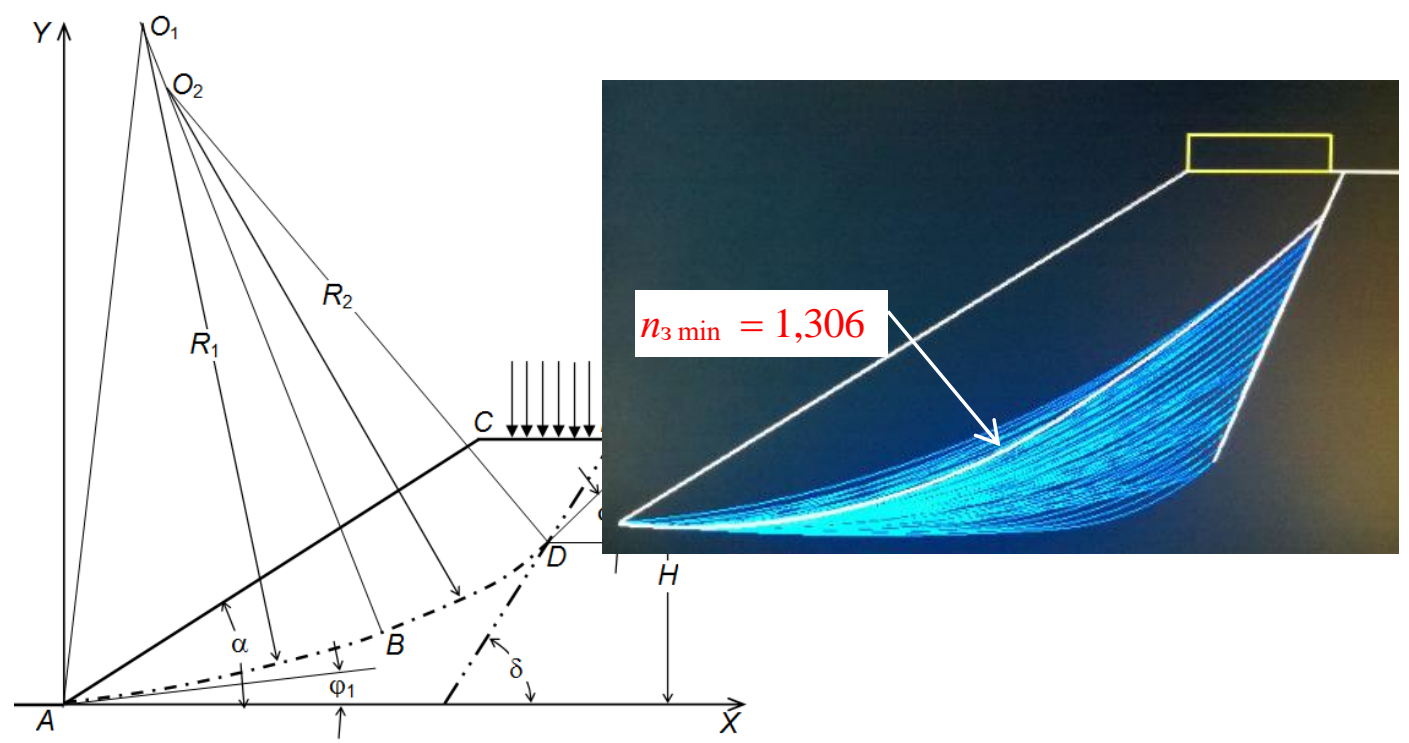

Fig. 2. Construction of sliding surfaces in a weakened bank.

Example. Source data: $\gamma=2.5 \mathrm{kN} / \mathrm{m}^{3} ; \rho=20^{\circ} ; \mathrm{C}=17.5 \mathrm{kPa}$; angle of internal friction and contact grip $\rho^{\prime}=10^{\circ}$ and $\mathrm{C}^{\prime}=10 \mathrm{kPa} ; \mathrm{H}=23 \mathrm{~m} ; \alpha=30^{\circ} ; \delta=65^{\circ} ; \mathrm{Q}=10 \mathrm{kPa}$; the load is distributed from the edge of the slope to a distance of $10 \mathrm{~m}$. The statistics of random parameters $\gamma, \rho, C, \rho^{\prime}, C^{\prime}$ are determined by the normal distribution. $\mathrm{n}_{3}$ normal $=1.3$.

Deterministic block: initial value of slope angle, $\alpha=30^{\circ}, \mathrm{n}_{3 \min }=0,976$; first correction, $\alpha=25^{\circ}, \mathrm{n}_{3 \min }=1,162$; second correction, $\alpha=23^{\circ}, \mathrm{n}_{3 \min }=1,306$.

Simulation block: risk level $\mathrm{R}=0,87$.

Slope stability assessment by the polygon force method. Software implementation of the force polygon method allows to abandon labor-intensive graphical constructions. The algorithm for the object stability assessment is based on axioms and theorems of analytic 
geometry. The program automatically determines the coordinates of the force vectors in the compartments, Fig. 3, the cycle ends with the definition of the discrepancy - characterizing the "non-closeness" of the polygon of forces. The physical and technical characteristics of rocks with a safety factor of less than one are put to the program input $\rho^{\prime}=\operatorname{arctg}\left(\operatorname{tg} / n_{3}\right)$ and $C^{\prime}=\mathrm{C} / n_{3}$. After checking the discrepancy, the margin in the characteristics increases with a given step and a new construction of the polygon of forces is performed. This procedure is repeated until the discrepancy reaches an acceptable value.

$a$

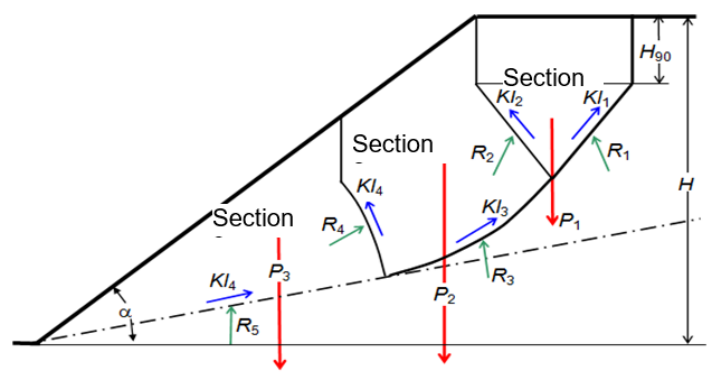

\begin{tabular}{|c|c|c|c|c|c|c|c|c|c|c|c|}
\hline $\begin{array}{c}\text { Section, } \\
\mathrm{i}\end{array}$ & $\begin{array}{l}\mathrm{P}_{\mathrm{i} 1}, \\
\mathrm{kN}\end{array}$ & $\begin{array}{c}1_{i 1}, \\
\mathrm{~m}\end{array}$ & $\begin{array}{c}\mathrm{l}_{\mathrm{i} 2}, \\
\mathrm{~m}\end{array}$ & $\begin{array}{l}\beta_{i 1}, \\
\text { deg. }\end{array}$ & $\begin{array}{l}\beta_{\mathrm{i} 2}, \\
\text { deg. }\end{array}$ & $\begin{array}{c}\mathrm{MK}_{\mathrm{i}}, \\
\mathrm{kPa}\end{array}$ & $\begin{array}{l}\mathrm{SK}_{\mathrm{i}} \\
\mathrm{kPa}\end{array}$ & $\begin{array}{l}\mathrm{M} \rho_{\mathrm{i}}, \\
\text { deg. }\end{array}$ & $\begin{array}{l}\mathrm{S} \rho_{\mathrm{i}}, \\
\text { deg. }\end{array}$ & $\begin{array}{c}\mathrm{M} \gamma_{\mathrm{i}}, \\
\mathrm{kN} / \mathrm{m}^{3}\end{array}$ & $\begin{array}{c}\mathrm{S} \gamma_{\mathrm{i}}, \\
\mathrm{kN} / \mathrm{m}^{3}\end{array}$ \\
\hline 1 & 9120 & 18 & 18 & 55 & 125 & 80 & 2,5 & 30 & 10 & \multirow{3}{*}{24} & \multirow{3}{*}{3} \\
\hline 2 & 15360 & 26,5 & 24 & 36 & 114 & 80 & 2,5 & 30 & 10 & & \\
\hline 3 & 15000 & 50 & - & 10 & - & 40 & 1,25 & 16 & 5 & & \\
\hline
\end{tabular}

$b$

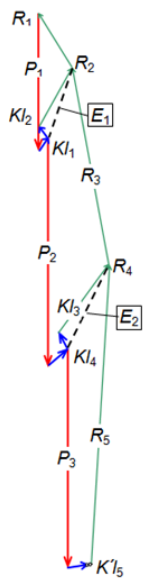

Fig. 3. To the calculation of the stability of slopes by the polygon of forces: $a$-alculation scheme and source data; $b$ - construction of the polygon of forces.

The safety factor is estimated without constructing of the force polygon:

$\mathrm{P} 1(1)=917,7 \mathrm{P} 2(1)=-7809,4 \mathrm{P} 3(1)=1334,0$

$\mathrm{P} 4(1)=-3249,4$ P5 ( 1$)=3,729001 \mathrm{E}-04 \mathrm{P} 6(1)=-6498,713$

$\mathrm{P} 1(2)=2823,407 \mathrm{P} 2(2)=-21784,8 \mathrm{P} 3(2)=2268,499$

$\mathrm{P} 4(2)=-19360,07$ P5( 2$)=1955,702$ P6( 2$)=-19835,9$

$\mathrm{P} 1(3)=5011,869 \mathrm{P} 2(3)=-36398,91 \mathrm{P} 3(3)=-4352,257$

$\mathrm{P} 4(\mathrm{l})=-38050,06 \mathrm{P} 5(\mathrm{l})=5011,869$ P6( 3 ) $=-36398,91$

$\mathrm{K}=1$ DISCREPANCY NVI $(\mathrm{K})=9364,125$ N3( 1 )=,9

$\mathrm{P} 1(1)=750,8637 \mathrm{P} 2(1)=-8047,656 \mathrm{P} 3(1)=1800,625$

$\mathrm{P} 4(1)=-3487,657$ P5 ( 1$)=2,727915 \mathrm{E}-04 \mathrm{P} 6(1)=-6975,311$

$\mathrm{P} 1(2)=2310,06 \mathrm{P} 2$ ( 2 ) $=-22274,83 \mathrm{P} 3(2)=3887,941$

$\mathrm{P} 4(2)=-17784,09$ P5( 2$)=1600,12$ P6( 2$)=-20680,28$

$\mathrm{P} 1(3)=4100,62 \mathrm{P} 2(3)=-36959,11 \mathrm{P} 3(3)=314,2838$

$\mathrm{P} 4(\mathrm{l})=-37626,74 \mathrm{P} 5(\mathrm{l})=4100,62 \mathrm{P} 6(\mathrm{l})=-36959,11$

$\mathrm{K}=3$ DISCREPANCY NVI $(\mathrm{K})=3786,336 \mathbf{N 3}(\mathbf{3})=\mathbf{1 , 1}$

$\mathrm{P} 1(1)=635,3463 \mathrm{P} 2(1)=-8212,632 \mathrm{P} 3(1)=2199,345$

$\mathrm{P} 4(1)=-3652,633 \mathrm{P} 5(1)=2,52226 \mathrm{E}-04 \mathrm{P} 6(1)=-7305,263$

$\mathrm{P} 1(2)=1954,666 \mathrm{P} 2(2)=-22614,09 \mathrm{P} 3(2)=5078,444$

$\mathrm{P} 4(\mathrm{~L})=-17136,1 \mathrm{P} 5(\mathrm{2})=1353,948 \mathrm{P} 6(2)=-21264,85$

$\mathrm{P} 1(3)=3469,755 \mathrm{P} 2(3)=-37346,94 \mathrm{P} 3(3)=3512,462$

$\mathrm{P} 4(\mathrm{3})=-37339,41 \mathrm{P} 5(\mathrm{3})=3469,755 \mathrm{P} 6(\mathrm{3})=-37346,94$

$\mathrm{K}=5$ DISCREPANCY NVI $(\mathrm{K})=-42,70728$ N3( $\mathbf{5})=\mathbf{1 , 3}$
$\mathrm{P} 1(1)=825,9501 \mathrm{P} 2(1)=-7940,421 \mathrm{P} 3(1)=1576,316$

$\mathrm{P} 4(1)=-3380,422$ P5( 1$)=2,98989 \mathrm{E}-04 \mathrm{P} 6(1)=-6760,842$

$\mathrm{P} 1(2)=2541,066$ P2 ( 2 ) $=-22054,32$ P3( 2 ) $=3153,148$

$\mathrm{P} 4(2)=-18382,99 \mathrm{P} 5(2)=1760,132$ P6( 2$)=-20300,31$

$\mathrm{P} 1(3)=4510,682 \mathrm{P} 2(3)=-36707,02 \mathrm{P} 3(3)=-1763,112$

$\mathrm{P} 4(\mathrm{3})=-37813,26 \mathrm{P} 5(\mathrm{l})=4510,682$ P6( 3 ) $=-36707,02$

$\mathrm{K}=2$ DISCREPANCY NVI $(\mathrm{K})=6273,794$ N3( 2 )= 1

$\mathrm{P} 1(1)=688,2918 \mathrm{P} 2(1)=-8137,018 \mathrm{P} 3(1)=2007,872$

$\mathrm{P} 4(1)=-3577,019$ P5 ( 1$)=2,796751 \mathrm{E}-04$ P6( 1$)=-7154,035$

$\mathrm{P} 1(2)=2117,555 \mathrm{P} 2(2)=-22458,6 \mathrm{P} 3(2)=4520,934$

$\mathrm{P} 4(2)=-17396,43$ P5 ( 2 ) $=1466,777$ P6( 2$)=-20996,93$

$\mathrm{P} 1(3)=3758,901 \mathrm{P} 2(3)=-37169,18 \mathrm{P} 3(3)=2041,537$

$\mathrm{P} 4(\mathrm{~s})=-37472$ P5( 3 ) $=3758,901$ P6( 3 ) $=-37169,18$

$\mathrm{K}=4$ DISCREPANCY NVI $(\mathrm{K})=1717,365$ N3( 4 )= 1,2

Slope margin of stability, $\mathrm{N} 3=1.297574$ 
Demonstration array of random values of stability margin coefficients

$\begin{array}{lllllllll}\mathbf{0 . 9 0 1} & \mathbf{0 . 9 1 6} & \mathbf{0 . 9 2 7} & \mathbf{0 . 9 3 5} & \mathbf{0 . 9 3 8} & \mathbf{0 . 9 4 5} & \mathbf{0 . 9 8 7} & \mathbf{0 . 9 8 9} & \mathbf{0 . 9 9 4} \\ \mathbf{0 . 9 9 5} & 1.015 & 1.024 & 1.035 & 1.061 & 1.064 & 1.067 & 1.073 & 1.075 \\ 1.085 & 1.085 & 1.094 & 1.095 & 1.103 & 1.106 & 1.123 & 1.131 & 1.142 \\ 1.146 & 1.165 & 1.167 & 1.175 & 1.183 & 1.184 & 1.186 & 1.187 & 1.191 \\ 1.198 & 1.198 & 1.199 & 1.209 & 1.210 & 1.214 & 1.216 & 1.218 & 1.226 \\ 1.233 & 1.237 & 1.250 & 1.259 & 1.260 & 1.273 & 1.278 & 1.281 & 1.282 \\ 1.284 & 1.288 & 1.292 & 1.294 & 1.296 & 1.301 & 1.315 & 1.317 & 1.320 \\ 1.320 & 1.328 & 1.334 & 1.340 & 1.345 & 1.351 & 1.354 & 1.356 & 1.361 \\ 1.361 & 1.361 & 1.364 & 1.364 & 1.368 & 1.378 & 1.395 & 1.397 & 1.400 \\ 1.408 & 1.412 & 1.422 & 1.427 & 1.428 & 1.429 & 1.431 & 1.433 & 1.451 \\ 1.454 & 1.479 & 1.483 & 1.487 & 1.496 & 1.500 & 1.506 & 1.507 & 1.509 \\ 1.522 & 1.523 & 1.529 & 1.529 & 1.532 & 1.537 & 1.565 & 1.567 & 1.572 \\ 1.578 & 1.585 & 1.614 & 1.630 & 1.662 & 1.679 & 1.698 & 1.700 & 1.763 \\ 1.785 & 1.794 & 1.819 & 1.835 & 1.839 & 1.860 & 1.981 & 2.048 & 2.117 \\ 2.400 & 2.400 & 2.400 & 2.400 & 2.400 & 2.400 & 2.400 & 2.400 & 2.400\end{array}$

The risk of slope deformation is $10 / 135=0.0741$.

Slope stability assessment based on the final element method is illustrated by two examples.

Example 1. The initial physical and mechanical characteristics of the pre-slope massif: elastic modulus $\mathrm{M}_{\mathrm{E}}=10000 \mathrm{kPa}, \mathrm{S}_{\mathrm{E}}=1000 \mathrm{kPa}$; Poisson ratio $\mathrm{M}_{\mu}=0,3, \mathrm{~S}_{\mu}=0,05$; spec. gravity; $\mathrm{M}_{\gamma}=24 \mathrm{kN} / \mathrm{m}^{3}, \mathrm{~S}_{\gamma}=2 \mathrm{kN} / \mathrm{m}^{3}$; internal friction angle $\mathrm{M}_{\rho}=15 \mathrm{deg}$., $\mathrm{S}_{\rho}=1,5 \mathrm{deg}$.; adhesion $\mathrm{M}_{\mathrm{C}}=10 \mathrm{kPa}, \mathrm{S}_{\mathrm{C}}=2 \mathrm{kPa}$.

Slope stability assessment is performed in the following order:

- initial physical and mechanical characteristics are generated by normally distributed random numbers (the first five numbers out of 135 are given):

\begin{tabular}{|c|c|c|c|c|}
\hline$E, \mathrm{kPa}$ & $\mu$ & $\gamma, \mathrm{kN} / \mathrm{m}^{3}$ & $\rho$, deg. & $C, \mathrm{kPa}$ \\
\hline 10261.26 & 0.382006 & $1,11,20,70403$ & 13.61936 & 6.305686 \\
\hline 9657.271 & 0.2930931 & 22.63546 & 15.6321 & 10.59468 \\
\hline 11295.8 & 0.3388793 & 25.31037 & 17.62062 & 11.56102 \\
\hline 10355.7 & 0.2335859 & 23.77033 & 15.43184 & 7.416532 \\
\hline 9406.764 & 0.26103 & 22.38637 & 16.61853 & 7.055937 \\
\hline
\end{tabular}

- a random number sensor plays 24 groups of characteristics out of 135, for each group according to the Z SOIL program in a flat setting (Fig. 4) the slope stability margin factors are determined: $1.06,1.16,1.11,1.01,1.21,1.17,1.27,0.95,1.20,1.05,1.03,1.06,0.97$, $1.15,1.17 .1 .00,1.18,121,1.34,1.13,1.21,1.10,1.20$;
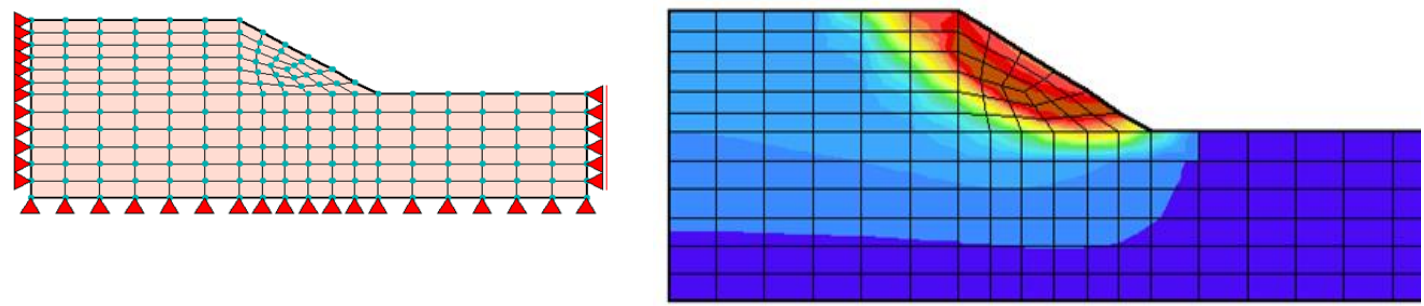

Fig.4. The mesh of finite elements and slope deformation. 
- bootstrap generation is performed according to B. Efron [9] of samples of 24 components in the amount of 1000 components (the first 18 of 1000 are given):

$$
\begin{aligned}
& 1.0111 .1090 .9781 .2651 .1911 .1981 .1261 .1881 .281 \\
& 1.0031 .0691 .0591 .1921 .2091 .1911 .1091 .1481 .095
\end{aligned}
$$

- the average value of the safety factor $n_{3} 1000=1.131$ is calculated and, according to the ratio (4) the level of geomechanical risk $\mathrm{R}=0.043$.

Example 2. The stability of the slope of the tailings dam is evaluated (Fig. 5). Source data: dam height $4 \mathrm{~m}$, horizontal slope laying in the til bay $12 \mathrm{~m}$, external load $6.25 \mathrm{kPa}$. Physical-mechanical characteristics: $\mathrm{M}_{\gamma}=25 \mathrm{kN} / \mathrm{m}^{3}, \mathrm{~S}_{\gamma}=7,5 \mathrm{kN} / \mathrm{m}^{3} ; \mathrm{M}_{\rho}=20 \mathrm{deg}$., $\mathrm{S}_{\rho}=6$ deg.; $\mathrm{M}_{\mathrm{C}}=17,5 \mathrm{kPa}, \mathrm{S}_{\mathrm{C}}=5,25 \mathrm{kPa}$.

In Fig. 5 a, b shows the finite element diagram of the dam and the cross section through the loaded section obtained in the PLAXIS 3D environment.

The results of deterministic and simulation estimations of slope stability and geomechanical risk are presented in Fig. 5, c, d. Note: the tailings dams belong to high hazard structures: in particular, negligence in the operation of a small dam with a height of $5 \mathrm{~m}$ of a gold mine on the river Seiba in the Krasnoyarsk Territory ended in mass deaths and an all-Russian tragedy.
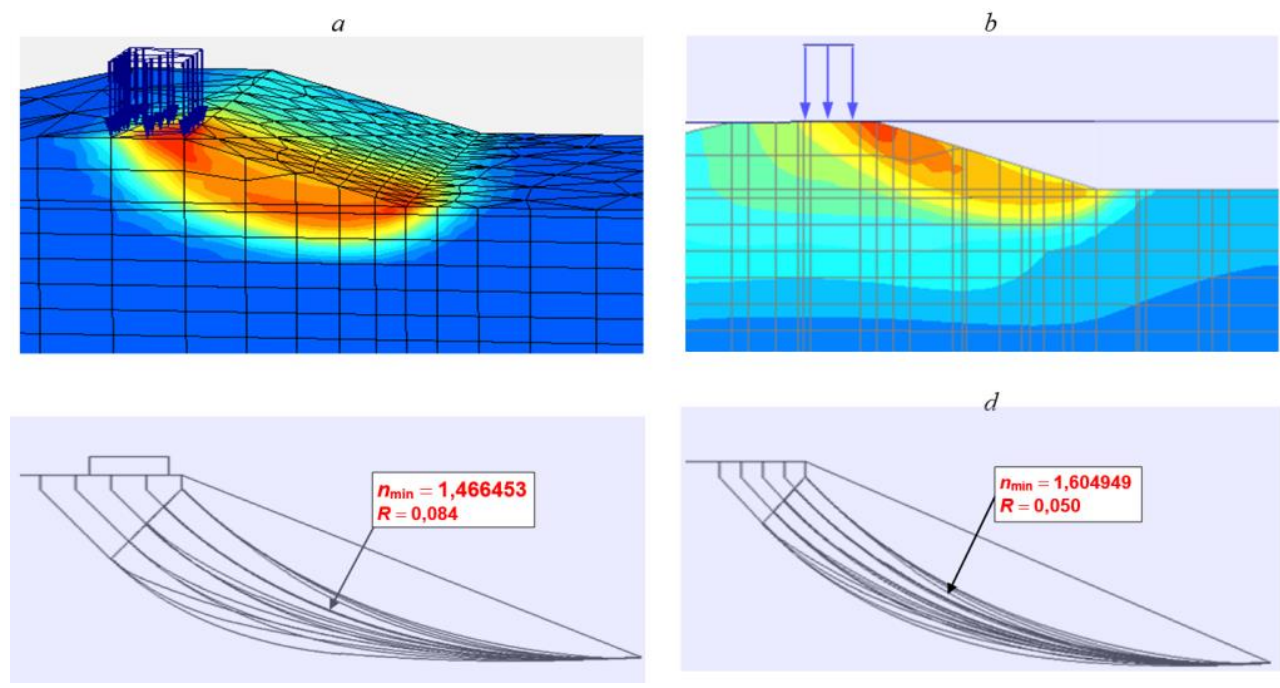

Fig. 5. Tailings dam: $a$ - a FEM design scheme; $b$ - general bias; $c, d$ - schemes to calculate the stability of the dam sections with external load and without external load.

\section{Retaining walls}

These simple structures, massively used in the construction of urban under soil structures in an open way, are unforgiving of any carelessness allowed in the design and construction of deep pits. The failure rate of retaining walls in the context of close urban development increases sharply, and the severity of the consequences of accidents increases as a result of additional economic costs, environmental damage to the urban environment, threats to human life and health. Indicative major accidents: the collapse of the building of the Institute of Statistics in Brussels (Belgium) into a pit under construction, accompanied by the death of 17 people [10], the resettlement of more than 1000 residents of Barcelona (Spain) from damaged buildings caused by deformations of the under-soil facility. Unfortunately, minor accidents are often found at domestic construction sites, a very typical emergency situation in dynamics is shown in Fig. 6. 


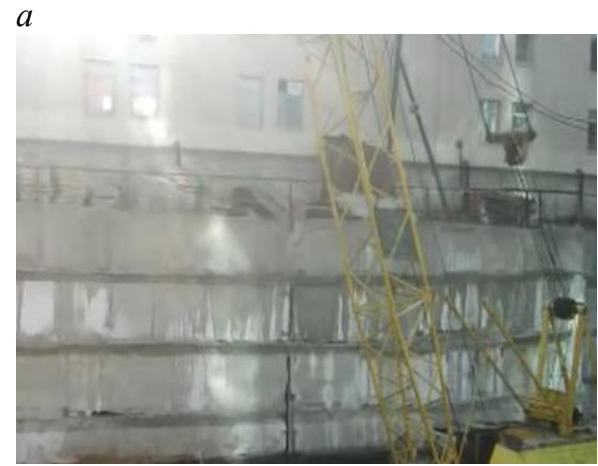

$c$
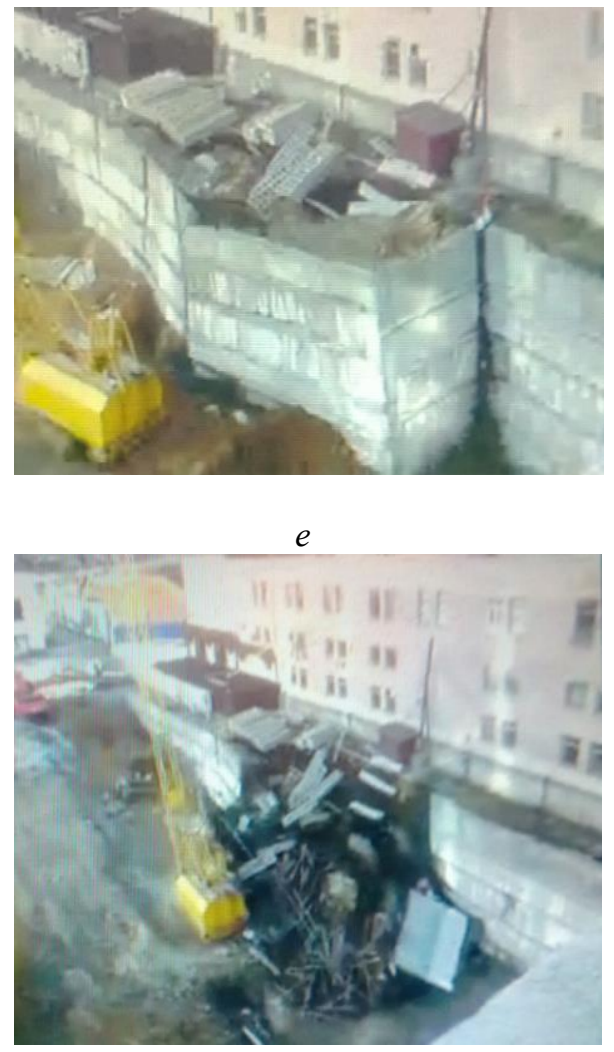

$b$

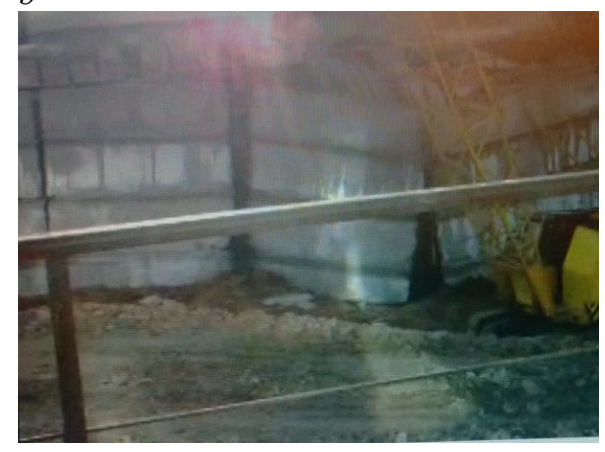

$d$
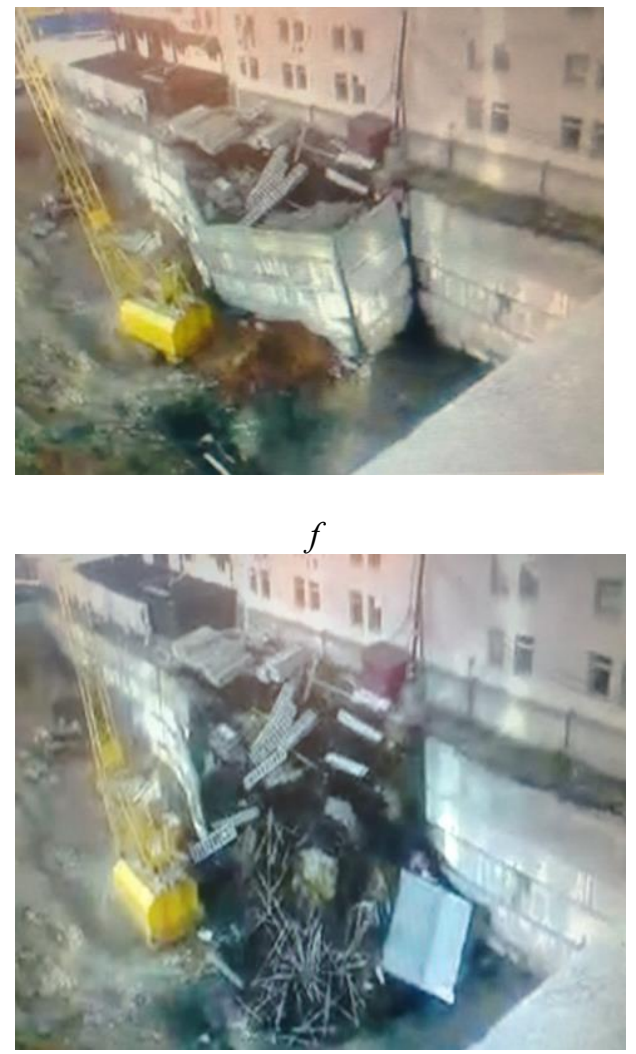

Fig. 6. Yekaterinburg. B. Central market territory. The dynamics of the destruction of the pit fence: $a$ - formation of a vertical crack; $b$ - crack development; $c$ - bend of the wall along the strike; $d$ development of bending deformations with simultaneous displacement of the wall; $e, f$ - collapse of the fence and displaced soil masses.

Pit fence stability assessment according to the deep shear scheme. Kranzes method. The design scheme for assessing the stability of the anchor fence with the construction of a power polygon that determines the condition of ultimate equilibrium is shown in Fig. 7. 
Stability assessment is carried out "on tipping" relative to point 1 , provided that the shear strength of the soils is overcome and the displacement of the soil mass occurs along a deep slip line $1 \div 5$. In accordance with the Kranzes method, power polygons are constructed (according to Fig. 7, b), then the optimal state of the "fence (pile) - soil - anchor" system is set, the angle of inclination of the anchor to the horizon, the height of the anchor in the pit, and the distance $l_{2}$ vary (see Fig. $7, a$ ).

Graphic constructions are performed by a special program, illustrated by a test case. Initial source data: pile height $H=20 \mathrm{~m}$, anchor mouth height from the surface $h_{\mathrm{a}}=9,8 \mathrm{~m}$, specific gravity of soil $\gamma=18 \mathrm{kN} / \mathrm{m}^{3}$, angle of soil internal friction $\rho=$ deg., anchor inclination angle $\omega=10 \mathrm{deg}$, external load on the benching $P=0 \mathrm{kPa}$, angle of internal friction on the surface of the fence $\delta \mathrm{deg}$., anchor tension force $T_{\mathrm{a}}=744,1 \mathrm{kN}$, reserve distance between the sliding surface and the embedment of the anchor, length of the anchor embedment $l_{2}=2 \mathrm{~m}$.
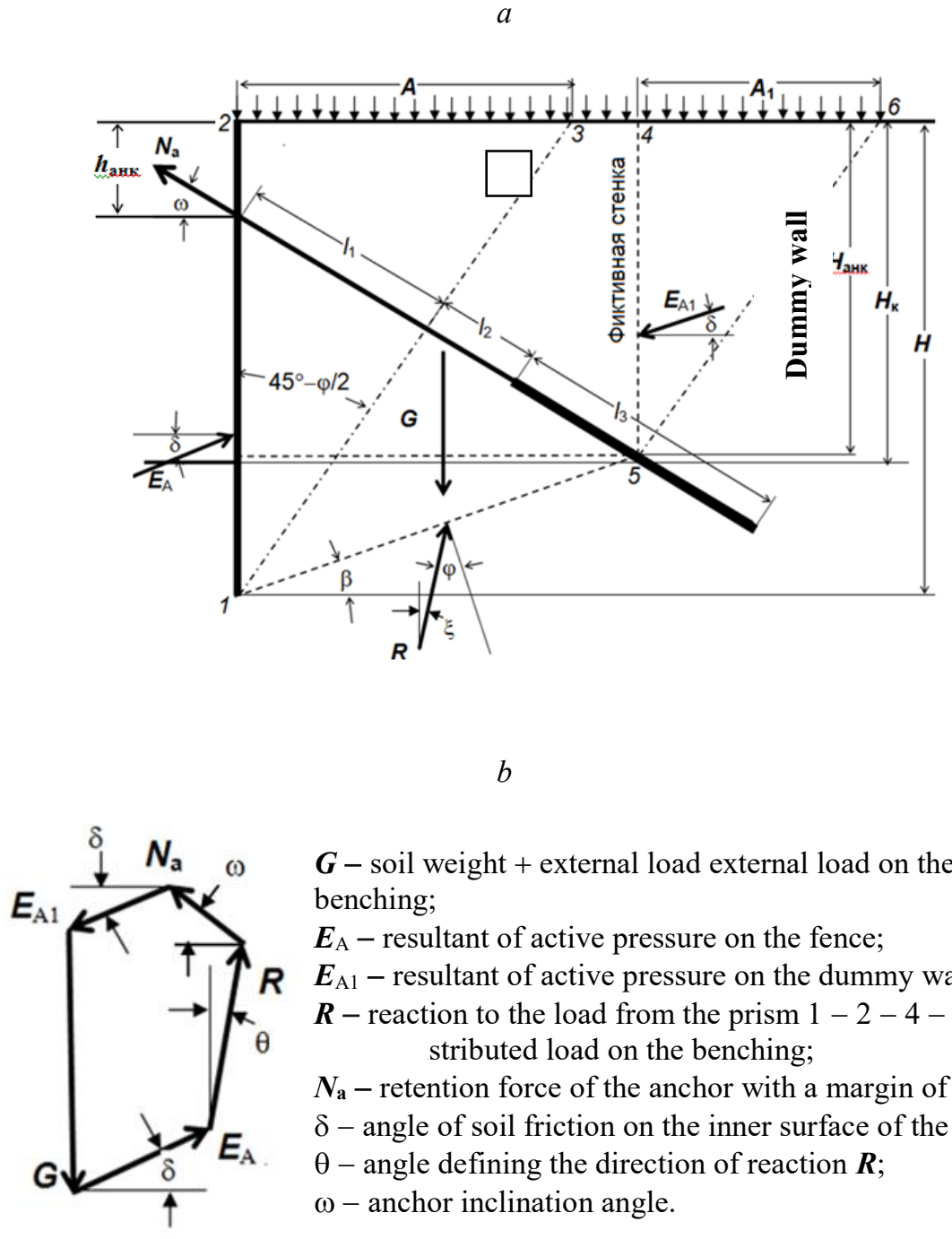

$\boldsymbol{G}$ - soil weight + external load external load on the benching;

$\boldsymbol{E}_{\mathrm{A}}-$ resultant of active pressure on the fence;

$\boldsymbol{E}_{\mathrm{A} 1}$ - resultant of active pressure on the dummy wall;

$\boldsymbol{R}$ - reaction to the load from the prism $1-2-4-5$ and

stributed load on the benching;

$N_{\mathrm{a}}$ - retention force of the anchor with a margin of 1.0;

$\delta$ - angle of soil friction on the inner surface of the wall;

$\theta$ - angle defining the direction of reaction $\boldsymbol{R}$;

$\omega-$ anchor inclination angle.

Fig.7. Calculation scheme (a), force polygon $(b)$. 
Deterministic block, force polygon vector $\mathrm{N}_{\mathrm{a}}=163.6953 \mathrm{kN}$, tipping margin factor $\mathrm{K}_{30}$ $=\mathrm{N}_{\mathrm{a}} / \mathrm{T}_{\mathrm{a}}=4.55$.

First correction: $h_{a}=12$ m. Results: $\mathrm{N}_{\mathrm{a}}=196.7837 \mathrm{kN}, \mathrm{K}_{30}=3.72$.

Second correction: $\mathrm{T}_{\mathrm{a}}=406,2 \mathrm{kN}$. Results: $\mathrm{N}_{\mathrm{a}}=196.7837 \mathrm{kN}, \mathrm{K}_{3 \mathrm{O}}=2.03$.

Simulation block: statistics: specific gravity, $\mathrm{kN} / \mathrm{m}^{3}, \mathrm{M}(1)=18, \mathrm{~S}(1)=5.4$; internal friction angle, $\mathrm{rad}, \mathrm{M}(2)=0.2268926, \mathrm{~S}(2)=6.806779 \mathrm{E}-02$.

Simulation Result: risk level: $\mathrm{R}=0.031$.

Pile anchor lining analysis. The main parameters subject to geomechanical analysis in the calculation of lining are the following: depth of embedment (driving) of the pile; distances between piles, anchors (spacers); height of their tiers above the bottom of the pit; sections of piles, anchors (spacers) and girders.

The design schemes of the pit fence are shown in Fig. 8. Calculation of a single-tier lining is performed according to the formulas and source data given in the methodological recommendations of the Central Scientific Research Institute of Construction [11]. Two provisions are the basis of the analysis method for the multi-tiered pit lining: 1 - calculation of the system in the interval from the surface to the bottom of the pit using methods practiced in structural mechanics; 2 - bending moments below the bottom of the pit and the pressure intensity of the pile on the soil are estimated taking into account the linearly varying coefficient of the bed at the depth of embedment.

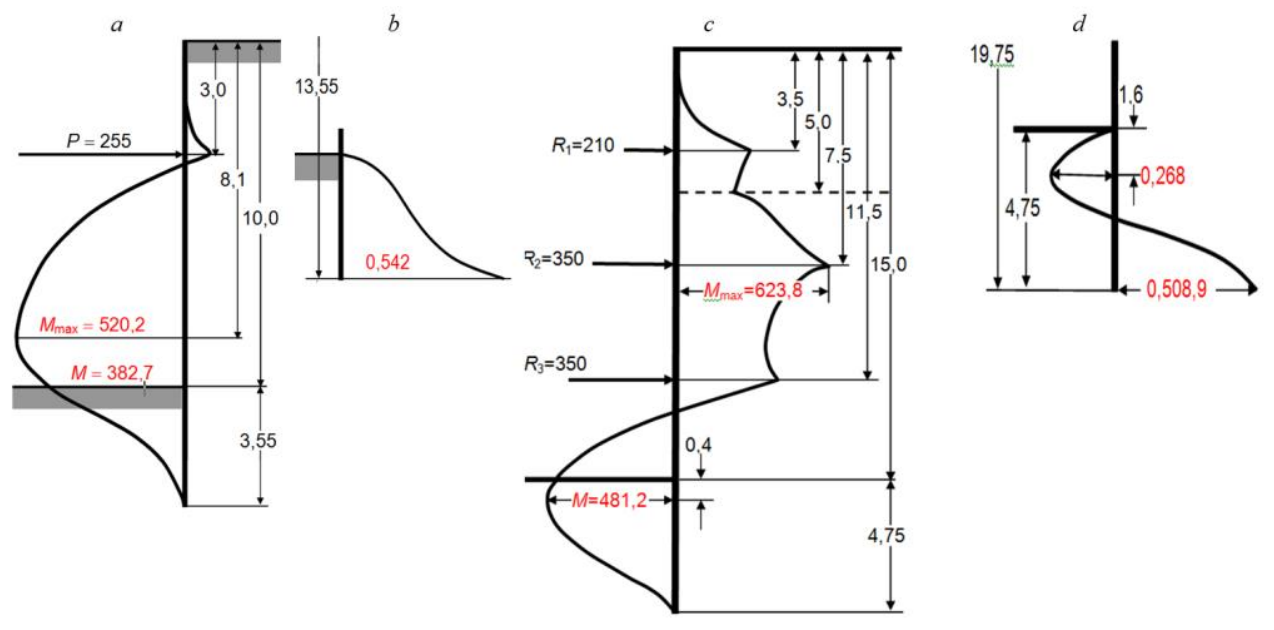

Fig. 8. Diagrams of bending moments, $\mathrm{kN} \mathrm{m}, \mathrm{a}, \mathrm{c}$ and intensity of pile pressure on the soil, $\mathrm{MPa} b, \mathrm{~d}$, load in $\mathrm{kN}$.

Example. Source data: Pit depth $H_{P}=10 \mathrm{~m}$; rocks specific gravity $\gamma=18 \mathrm{kN} / \mathrm{m}^{3}$; internal friction angle $\varphi=13^{0}$; adhesion $\mathrm{c}=0.022 \mathrm{MPa}$; belt position depth $\mathrm{h}_{\mathrm{P}}=3.0 \mathrm{~m}$; no vertical load; bearing capacity of the spacer $\mathrm{P}=225 \mathrm{kN}$.

Deterministic block. A measure of the effectiveness of the retaining structure is the safety factors $K_{3 \text { bend }}=R /(M / W)$ and $K_{3}$ int $=I_{l p} / I_{h}$, where $R$ - design resistance of the pile material to bending, $\mathrm{M}$ and $\mathrm{W}-$ bending moments of the pile and the moment of its axial resistance, $\mathrm{I}_{\mathrm{lp}}$ - limit pressure of the pile on the soil, $\mathrm{I}_{\mathrm{h}}$ - pressure intensity of piles at depth.

The calculation results at the depth of $3.55 \mathrm{~m}$; safety factor for piles bending above the bottom of the pit 1.033; safety factor for piles bending in embedment 1.404; safety factor for the pressure intensity of piles on the soil at a depth of $13.55 \mathrm{~m}$; safety factor for the pressure intensity of piles on the soil at a depth of $11.18 \mathrm{~m}$; 
The calculation options for the pile-anchor fence with different embedment depths are given in table. 2 .

Table 2. Results of the calculation of pile walls with a depth of $3.00 ; 3.55 ; 4.00 ; 5.50 \mathrm{~m}$.

\begin{tabular}{|c|c|c|c|c|c|c|c|}
\hline$t, \mathrm{~m}$ & $\begin{array}{l}\sigma_{t / 3} \\
\mathrm{MPa}\end{array}$ & $\begin{array}{c}0,95 \sigma_{\mathrm{lp} t / 3} \\
\mathrm{MPa}\end{array}$ & $\sigma_{t}, \mathrm{MPa}$ & $\begin{array}{c}0,95 \sigma_{\mathrm{lpt}} \\
\mathrm{MPa}\end{array}$ & $\begin{array}{c}\text { MW1, } \\
\text { MPa }\end{array}$ & $\begin{array}{c}\text { MW2, } \\
\text { MPa }\end{array}$ & $\begin{array}{c}R, \\
\mathrm{MPa}\end{array}$ \\
\hline \multirow{2}{*}{3.55} & 0.122 & 0.269 & 0.542 & 0.570 & \multirow{4}{*}{203} & \multirow{4}{*}{150} & \multirow{7}{*}{210} \\
\hline & \multicolumn{2}{|c|}{$0.269 / 0.122=2.195$} & \multicolumn{2}{|c|}{$0.570 / 0.542=1.050$} & & & \\
\hline \multirow{2}{*}{4.00} & 0.171 & 0.291 & 0.307 & 0.623 & & & \\
\hline & \multicolumn{2}{|c|}{$0.291 / 0.171=1.701$} & \multicolumn{2}{|c|}{$0.623 / 0.307=2.030$} & & & \\
\hline \multirow{3}{*}{5.50} & \multirow{2}{*}{\multicolumn{2}{|c|}{$\begin{array}{r}0.165 \\
0184\end{array}$}} & \multirow{2}{*}{\multicolumn{2}{|c|}{$\begin{array}{r}0.279 \\
0.427 \\
\end{array}$}} & \multirow{3}{*}{178} & \multirow{3}{*}{117} & \\
\hline & & & & & & & \\
\hline & \multicolumn{2}{|c|}{$0.184 / 0.165=1.111$} & \multicolumn{2}{|c|}{$0.426 / 0.279=1.531$} & & & \\
\hline
\end{tabular}

Safety margins: $K_{3 \text { bend } 1}=1,1784 K_{3}$ bend $2=1,802 ; K_{3}$ int $1=1,111 ; K_{3 \text { int1 }}=1,531$.

Simulation block: soil specific gravity, $\mathrm{kN} / \mathrm{m}^{3}, \mathrm{M}(1)=18, \mathrm{~S}(1)=2,7$; internal friction angle, $\mathrm{rad}, \mathrm{M}(2)=0.2269, \mathrm{~S}(2)=3.4034 \mathrm{E}-02$; adhesion, $\mathrm{MPa}, \mathrm{M}(3)=0.022, \mathrm{~S}(3)=$ 0.0066 .

The reliability of the fence for all four state indicators for the $t=3.55 \mathrm{~m}$ variant $(0.1268657,0.141791,0.4626866,0.5259259)$ is insufficient. Correction is required for the parameters of the depth of spacers belt installation; geometrical characteristics of the pile: pile depth; bearing capacity of spacer (anchor).

After correction of the pile embedment depth to $5.5 \mathrm{~m}$, the reliability indicators are as follows: SPR2 / STD: 0.724; SPR1 / SD: 0.851; MW1 / RUC: 1.00; MW2 / RUC: 0.946.

Analysis of the dowel fastening parameters of the deep pits walls. Dowel fastening is used for walls and steep slopes of construction pits and excavations with a depth of, as a rule, not more than $15 \mathrm{~m}$ in the absence of aquifers and difficult to drain soils as temporary, and when proper anti-corrosion protection is applied -and as permanent. It is allowed for use in dusty-clay soils, with the exception of subsidence and swelling ones. As a result of the friction forces generated by prestressed dowels (reinforcing rods) in the soil massif, the complex of the pit dowel lining produces "fictitious adhesion" in the latter, linking the massif along the length $L$ into a single - specific retaining wall of a massive type. This is the formal difference between the dowels and the anchors, which transmit the soil pressure in the caving prism beyond the sliding surface.

The design diagram of the dowel fastening of the retaining wall is shown in Fig. 8.

The main parameters characterizing the complex of the pit wall dowel mounting include the following: inclined length of the dowels (reinforcing rods, in particular, tubular screw rods "Titan", "Atlant") $l$; horizontal projection of the length of the dowel $L$; distance between the dowels along the height of the pit $a$; distance between the dowels along the strike of tier $b$; tilt slope of the pit, counted from the vertical $\alpha$; angle of inclination of the dowel to the horizon $\omega$; dowels diameter $d_{\mathrm{a}}$; protective coating thickness $t$. The rational calculation of the dowel lining requires multiple correction according to the listed parameters. 


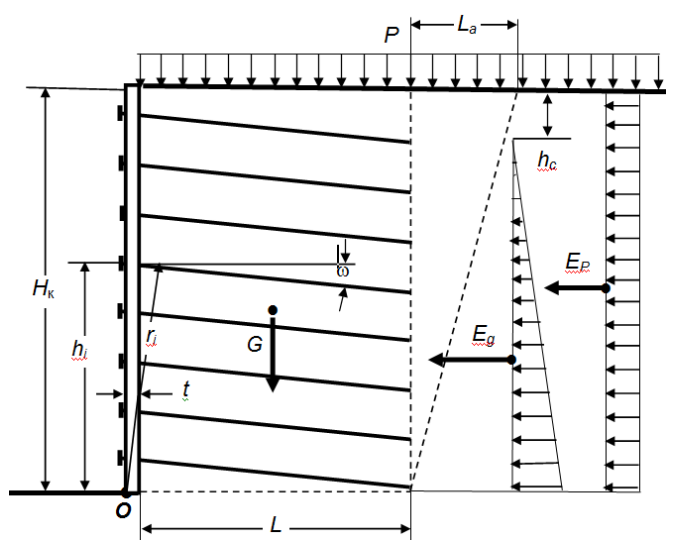

Source data for work with the USMU program: Pit depth $H_{P}=15 \mathrm{~m}$. Distance between the pins vertically $a=1 \mathrm{~m}$. Distance between the dowels along the strike of the wall $b=1 \mathrm{~m}$. Distance from the lower dowel to the bottom of the pit $a_{1}=1 \mathrm{~m}$. Soil specific gravity $\gamma=23,5 \mathrm{kN} / \mathrm{m}^{3}$. Internal friction angle of the soil $\varphi=25^{\circ}$. A ngle of friction of the soil on the dowel material $\mu=25^{\circ}$. Soil adhesion $C=20 \mathrm{kPa}$. Length of the fixed soil block in the strike cross $L=12 \mathrm{~m}$. Dowel tilt angle $\omega=10^{\circ}$. External load on the berm of the pit $P=10 \mathrm{kPa}$. Diameter of the hardened zone around the dowel $D$ $=0,032 \mathrm{~m}$ Dowel holding force $T=0 \mathrm{kN}$. Shotcrete tensile resistance $\mathrm{R}_{\mathrm{sc}}=1250 \mathrm{kN}$. Poisson ratio for shotcrete $\mu_{\mathrm{y}}==0,2$. General partial factor $\gamma_{n}=1,25$. Condition load effect factor $\gamma_{d}=0,9$. Load effect factor $\gamma_{f}=1,2$.

Fig.9. Calculation scheme and source data of the dowel fixing of the pit wall.

Deterministic block

The results obtained in the initial version: the number of dowels $\mathrm{N}=14$; length of the fixed soil block $\mathrm{L}=12 \mathrm{~m}$; dowel inclination angle $\omega=10^{\circ}$; effective adhesion $\mathrm{C}^{\prime}=$ $=105,6 \mathrm{kPa}$; safety factor for the rollover condition of the fixed block $\mathrm{K}_{3}$ rol $=3,16$; safety factor according to the condition of the shift of the fixed block $\mathrm{K}_{3 \text { shift }}=1,12$; thickness of the shotconcrete coating $\theta=0,073 \mathrm{~m}$; condition $h_{c}<a$ is fulfilled $H_{c}=2,67 \mathrm{~m}, a=1 \mathrm{~m}$; condition $\mathrm{H}_{90} \leq \mathrm{H}_{\mathrm{p}}$ isn't fulfilled $\mathrm{H}_{90}=14,1 \mathrm{~m}, \mathrm{H}_{\mathrm{p}}=15 \mathrm{~m}$.

Correction 1: $\mathrm{a}=1 \mathrm{~m} ; \mathrm{a}_{1}=1 \mathrm{~m} ; \omega=10^{\circ}$.

Correction 2: $\mathrm{b}=1 \mathrm{~m}$.

The results after corrections: distance between the dowels vertically $\mathrm{a}=\quad=0,65 \mathrm{~m}$; distance between the dowels along the strike of the wall $\mathrm{b}=1 \mathrm{~m}$; dowel quantity $\mathrm{N}=21$; length of the fixed soil block $\mathrm{L}=12 \mathrm{M}$; dowel inclination angle $\omega=10^{\circ}$; effective adhesion $\mathrm{C}^{\prime}$ $=121,8 \mathrm{kPa}$; safety factor for tipping condition $\mathrm{K}_{3 \mathrm{rol}}=3,29$; safety factor for shift condition of fixed block $\mathrm{K}_{3}$ shift $=1,13$; thickness of shotcrete coating $\theta=0,07 \mathrm{~m}$; condition $\mathrm{h}_{\mathrm{c}}<\mathrm{a}$ is fulfilled $\mathrm{H}_{\mathrm{c}}=2,67 \mathrm{~m}, \mathrm{a}=0,65 \mathrm{~m}$; condition $\mathrm{H}_{90} \leq \mathrm{H}_{\mathrm{p}}$ is fulfilled $\mathrm{H}_{90}=16,28 \mathrm{~m}, \mathrm{H}_{\mathrm{p}}=15 \mathrm{~m}$.

Simulation block. Number of demonstration generations is 135 , number of random arrays at the output of the model -5 , number of random parameters - 6: $\gamma, \rho, \mathrm{C}, \gamma_{\mathrm{n}}, \gamma_{\mathrm{d}}, \gamma_{\mathrm{f}}$.

Statistics of random parameters: $\mathrm{M}(1)=23.5 \mathrm{kN} / \mathrm{m}^{3} ; \mathrm{M}(2)=0,436332 \mathrm{rad} ; \mathrm{M}(3)=20$ $\mathrm{kPa} ; \mathrm{M}(4)=1,25 ; \mathrm{M}(5)=0,9 ; \mathrm{M}(6)=1,2 ; \mathrm{S}(1)=3,525 \mathrm{kN} / \mathrm{m}^{3} ; \mathrm{S}(2)=0,0654498 \mathrm{rad} ; \mathrm{S}(3)$ $=6 \mathrm{kPa} ; \mathrm{S}(4)=\quad=0,125 ; \mathrm{S}(5)=0,05 ; \mathrm{S}(6)=0,1$.

Distributions: $\gamma, \rho, C-$ normal; $\gamma_{\mathrm{n}}, \gamma_{\mathrm{d}}, \gamma_{\mathrm{f}}-$ one-side normal.

Reliability of the dowel lining by factors: safety factor by the condition of the tipping of the fixed block - 1.00; safety factor according to the condition of the shift of the fixed block 0,852; shotcrete coating thickness 0.83 ; condition $h_{c}<a$ 1,00; condition $H_{90} \leq H_{p} 0.911$.

\section{Discussion of the given materials}

In the given format, eight geomechanical situations perform demonstration and introductory functions. More generally, the presented material is recommended as computer analogues of new adapted solutions with the subsequent transition to professional-level models that provide high quality geomechanical analysis. The basis for the formation of such models is the reference program simulation designer. The simulation designer provides for the use of 
traditional random number generators based on the laws of normal, one-sided normal, exponential, Weibull distributions and non-standard generators for Gram-Charlier distribution and bootstrapping. The area of unconditional application of the normal distribution is limited by the probability of a normality hypothesis of $\square 0.85$, confirmed by the non-parametric Shapiro-Wilk agreement W-criterion, established by software. Probability above 0.75 provides indicative judgments about the properties of rocks and mining conditions. The normal distribution has no alternative if probabilistic interpretations of the normative coefficients of limit states, etc., obtained from the data of processing numerous experiments using the " 3 sigma" principle, are introduced into the simulation model. The generation volume $\mathrm{V}$ from 10,000 to $1,000,000$ on a home computer according to the updated GOST R 54500.3.1-2011 and GOST R ISO 28640-2012 is ensured by the sequential generation of 500 random numbers in a cycle of $\mathrm{V} / 500$ series. The modified designer provides a three-stage rejection of errors generated by the input-output random arrays, and an automatic estimation of the sensitivity of random parameters.

An integrated deterministic-probabilistic approach improves the quality of the considered geomechanical solutions, but at the same time does not guarantee its radical improvement. Due to imperfections in geotechnical exploration it is possible to skip mixers, tectonic disturbances, and local weakened zones. In this regard, a very promising measure for facilities with a high degree of responsibility is preventive monitoring aimed at identifying trends in the geomechanical situation $[12 \div 15]$.

\section{Conclusion}

The relevance and advantages of the integrated deterministic-probabilistic approach are confirmed by eight adapted examples that reflect the typical geomechanical schemes implemented in the design and operation of slopes and retaining walls of mining structures. A distinctive feature of the deterministic blocks of the situations considered is automatic correction, which optimizes the final deterministic results. The quality of the simulation component of the complex, the availability of simulation technologies to a wide range of potential users, and the speed of their implementation on ordinary computer equipment are noted. In addition to demonstration and introductory functions, adapted examples are the analogues for obtaining such solutions and, together with the "simulation designer" reference program, are a complete basis for the transition to the formation of complex models of a professional level.

\section{References}

1. B. D. Polov, N. G. Valiev, K. V. Kokarev, Mining Journal, 1, 66 (2016)

2. B. D. Polov, N. G. Valiev, K. V. Kokarev, Mining Journal, 12, 8 (2016)

3. G. I. Falin, Monte Carlo method in risk theory, https://www.math/msu.su.htm/

4. J. Mun. Modeling Risk: Applying Monte Carlo Simulation, Real Options Analysis, Forecasting, and Optimization Techniques, 480 (2006)

5. S. Hencher, Practical rock mechanics. Boca Ration London, 346 (2015)

6. Swedish Geotechnical Socity, 72 (2017)

7. B. D. Polov, M. N. Volkov, D. V. Mikhailov, D. A. Romanov, P. K. Tokarev, D. I. Kharchenko, Mining Journal, 7, 40 (2013)

8. L. Zacs, Statistical evaluation, 598 (1976)

9. B. Efron, Bootstrap methods. Another look at the jackknife, 7(1), 1 (1979)

10. R. Ribitsky, Damage and defects of building structures, 232 (1982)

11. Guidelines for the design of pile lining in the pits of the subways, 87 (1986) 
12. D. H. Stewart, G. J. Reid, CIM Bulletin, 81(917), 71 (1988)

13. S. Nunu, FTPRPI, 5, 114 (2018)

14. Manda-Maula, E. Kaunda R.B., FTPPRI, 1, 116 (2019)

15. I. V. Zyryanov, O. V. Zoteev, V. D. Baryshnikov, V. V. Pul, Mining Journal, 2, 21 (2019) 